\begin{tabular}{|c|c|c|c|c|}
\hline $\begin{array}{c}\text { Nature of cross } \\
\delta\end{array}$ & $\begin{array}{l}\text { Percent- } \\
\text { age of of } \\
\text { insemin- } \\
\text { ated }\end{array}$ & $\begin{array}{l}\text { Percentage } \\
\text { of insemin- } \\
\text { ated } 99 \text { liv- } \\
\text { ing over } 21 \\
\text { days which } \\
\text { produced } \\
\text { pupæ }\end{array}$ & $\begin{array}{l}\text { No. of pupæ } \\
\text { produced } \\
\text { per insemin- } \\
\text { atcd } \text { living } \\
\text { over } 21 \text { days }\end{array}$ & $\begin{array}{l}\text { Average } \\
\text { life of } \\
\text { of in } \\
\text { days }\end{array}$ \\
\hline 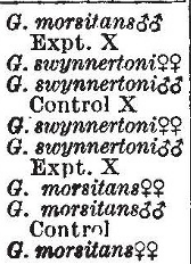 & $\begin{array}{l}92 \%(37) \\
80 \%(12) \\
96 \%(45) \\
76 \%(19)\end{array}$ & $\begin{array}{l}10 \%(31) \\
100 \%(7) \\
24 \%(33)\end{array}$ & $\begin{array}{l}0 \cdot 1 \quad(3) \\
2 \cdot 4(17)\end{array}$ & $\begin{array}{l}70(40) \\
61(12) \\
68(47) \\
75(19)\end{array}$ \\
\hline
\end{tabular}

N.B.-The numbers in brackets give the totals on which the percentages or averages are based; these are not the same throughout the table, as some females, counted as inseminatcd on the evidence of dissection, did not live long enough to produce pupæ, and also some of the females which were used to give the average life wer not dissected to show insemination.

pallidipes mated with but failed to inseminate a female $G$. morsitans, and four male $G$. pallidipes mated with and inseminated four female $G$. swynnertoni, none of which had offspring.

The numbers of tsetse in these experiments were limited by the amount of work involved in their maintenance; to feed these adequately took six African-assistants full time daily, including Sundays. The longevities of the various batches are not significantly different from each other by Student's $t$ test, nor are the percentages of each group, inseminated or not, significantly different by the $\chi_{c}$ test, but the number of inter-specifically mated females that produced and numbers of pupæ produced by them are significantly smaller than their controls ( $\chi_{c}$ test).

Other experiments, in which equal numbers of male and female $G$. swynnertoni, $G$. morsitans and $G$. pallidipes were mixed in a cage $30 \times 30 \times 30 \mathrm{~cm}$., showed that mating between $G$. swynnertoni and $G$. morsitans not only occurred as readily as between the opposite sexes of the same species when no choice was offered, but also took place at random, but G. pallidipes did not mate with either, nor did any of the male $G$. swynnertoni or $G$. morsitans mate with $G$. pallidipes. A field experiment releasing 600 G. morsitans from pupæ in a $G$. swynnertoni area by Dr. C. H. N. Jackson, of this Department, showed similar results to those obtained in the laboratory. The recaptured females were kept alive; and the male genitalia of the offspring were examined.

The male hybrids have distinct genitalia and show affinities to the female parent. All the hybrids were similar to $G$. swynnertoni in external markings, contrary to Corson's observations. Both types of male and female hybrids have been crossed with each other and with pure-bred male and female $G$. swynner. toni and $G$. morsitans. The male hybrids inseminate the females, both hybrid and pure-bred, but none has reproduced or showed signs of successful fertilization. So far attempts to cross female hybrids with pure-bred males of both species have failed. Though the hybrid females were laboratory-produced flies, they lived even longer than their female parents, averaging $106 \cdot 0$ days.

Experiments have also shown that a few hours after a female is inseminated she is no longer attractive to males and will not permit further coitus.

Work is being continued with other species and pupæ of the same species collected in other areas.
A field-scale experiment to exterminate $G$. suynnerton $i$ by releasing large numbers of $G$. morsitans has been begun in an isolated block of scanty $G$. swynnertoni country. It appears likely that $G$. morsitans would be unable to survive permanently in the area.

It is hoped to publish full details of this work shortly elsewhere. I am indebted to Mr. W. H. Potts and Dr. C. H. N. Jackson for their help and co-operation in this work, and to Mr. S. Napier Bax, the acting director, for permission to publish this.

Tsetse Research Department, F. L. VANDERPLANK. Old Shinyanga,
Tanganyika Territory.
Aug. 2l.

${ }^{1}$ Corson, J. F., J. Trop. Med. and Hyg. (April 1932).

Potts, Bull. Ent. Res., 28, 129 (1937), and unpublished data.

\section{Fertilization of $A$. maculipennis var. labranchiae in the Laboratory}

A. maculipennis var. labranchice is reported to swarm readily in a small cage $(1 \mathrm{~m}$. high and $50 \mathrm{~cm}$. wide) if a blue light of intensity about 3 f.c. at a distance of $30 \mathrm{~cm}$. is placed on top of the cage ${ }^{1}$. No record is known of laboratory mating of this variety without these experimental conditions.

A. maculipennis var. labranchioe was reared in the laboratory from eggs, and the adults allowed to emerge in a cage of wire mesh, dimensions $47 \mathrm{~cm}$. $\times$ $47 \mathrm{~cm}$. $\times 60 \mathrm{~cm}$. The cage was situated approximately 5 metres from the window of the laboratory, and the end nearest the window covered with a damp cloth. Under these conditions labranchioe fed readily at any hour of the day on an arm introduced into the cage. After a period of ten days, viable eggs were laid in bowls of tap-water in the cage, although no artificial light of any kind was provided. Swarming was not observed.

The experiments are continuing.

C/o D.D.M.S.,

A.F.H.Q., C.M.F.

${ }^{1}$ Batcs, M., and Hackett, L. W., Verhand. VII Internat. Kong. Ent., 3. 1555 (1938).

\section{Relation of 'Folic Acid' to the Nutri- tional Requirements of the Mosquito Larva}

IN our investigations on the nutritional requirements of the larva of Aedes oegypti, our procedure has been based on the methods employed by Trager ${ }^{1}$. Various modifications have been introduced which make for increased accuracy of observation and clearer interpretation of the results. Thus larger groups of larvæ were used, each larva being placed in a separate tube and its stage of development noted every morning and evening. All liquid media were sterilized by Seitz filtration and the contents of the tubes tested for sterility at the conclusion of each experiment.

In media capable of supporting growth, we have constantly noted that the length of time taken to reach the second, third and fourth larval instars, as well as the pupa, depends directly on the degree of adequacy of the medium. On this also depends the proportion of larvæ surviving. By suitable choice of media it is possible to interrupt larval development 